\title{
Biogeographic patterns among seed-bearing and spore-bearing plants across the California Channel Islands
}

\author{
Benjamin E. Carter $1{ }^{1}{ }^{*}$ and C. MatT GUILLiams ${ }^{2}$ \\ ${ }^{1}$ Department of Biological Sciences, San Jose State University, San Jose, CA \\ ${ }_{2}^{2}$ Santa Barbara Botanic Garden, Santa Barbara, CA
}

\begin{abstract}
Spore-bearing and seed-bearing plants differ in their ability to colonize islands from mainland sources. To assess the importance of these differences, we investigated patterns of species richness and species composition for the native bryophyte, fern, and seed plant floras of the California Channel Islands. Native richness was regressed against island area, maximum elevation, distance to mainland, distance to nearest propagule source along prevailing wind trajectories, and latitude for the 3 plant groups. Ordinations, Mantel tests, randomization tests, and an analysis partitioning beta diversity into turnover and nestedness components were used to identify similarities and differences in species composition across the 3 groups. Patterns of species richness were mostly consistent across the 3 groups, with island area and maximum elevation being much more important than distance to mainland or distance from nearest propagule source. Patterns of species composition were also generally consistent across the 3 groups. The 3 floras exhibit similar patterns of compositional change across the archipelago and these patterns are not driven by geographic distance among islands. Island area and maximum elevation were significant predictors of compositional change, but the 2 distance metrics were not. The seed plant flora exhibited strong turnover between the 4 northern and 4 southern islands, while the bryophyte flora exhibited southern islands floras nested within those of northern islands. We interpret these findings as suggesting that ecological filtering is more important than dispersal limitation for developing both seed-bearing and spore-bearing plants on the islands.
\end{abstract}

Resumen.-Las plantas con esporas y las plantas productoras de semillas difieren en su capacidad para colonizar las islas desde el continente. Para evaluar la importancia de estas diferencias investigamos los patrones de riqueza y de composición de las especies en la flora de briofitas nativas, helechos y plantas con semillas de las Islas del Canal de California (California Channel Islands). La riqueza autóctona se analizó calculando el coeficiente de regresión contra las siguientes variables: (1) superficie de la isla, (2) elevación máxima, (3) distancia al continente, (4) distancia desde la fuente de propágulos más cercana, a lo largo de las trayectorias predominantes del viento y (5) latitud, de los tres grupos de plantas. Para identificar las similitudes y las diferencias en la composición de las especies de los tres grupos, se usó la técnica de ordenación, prueba de Mantel, prueba de aleatorización y un análisis dividiendo la diversidad beta en componentes de rotación y anidamiento. Los patrones de riqueza de las especies fueron, en su mayoría, consistentes en los tres grupos. Siendo la superficie de la isla y la elevación máxima mucho más importantes, que la distancia al continente o la distancia desde la fuente de propágulo más cercana. Por lo general, los patrones de composición de las especies también fueron consistentes en los tres grupos. Las tres floras de las islas mostraron patrones similares de cambio en su composición en todo el archipiélago y tales patrones no se relacionaron con la distancia geográfica entre las islas. La superficie de la isla y la elevación máxima fueron indicadores significativos del cambio en la composición. Sin embargo, las dos mediciones de la distancia no lo fueron. La flora de las plantas con semilla mostró un gran cambio en las cuatro islas del norte y en las cuatro islas del sur, mientras que la flora de briofitas presente en las islas del sur se anidaron dentro de la flora de briofitas de las islas del norte. Interpretamos estos hallazgos como un indicador de que el filtrado ecológico es más importante que limitar la dispersión para desarrollar plantas productoras de semillas y plantas con esporas.

Dispersal limitation is one of the most important factors determining species richness and species composition on islands. MacArthur and Wilson's (1967) theory of island biogeography posits that the ability of plants and other organisms to colonize islands decreases with increasing distance from the mainland, and increases (as does carrying capacity and therefore persistence) with island size. Island biogeography of plants differs from that of animals in several respects. Unlike most animals, plants may colonize

*Corresponding author: benjamin.carter@sjsu.edu 


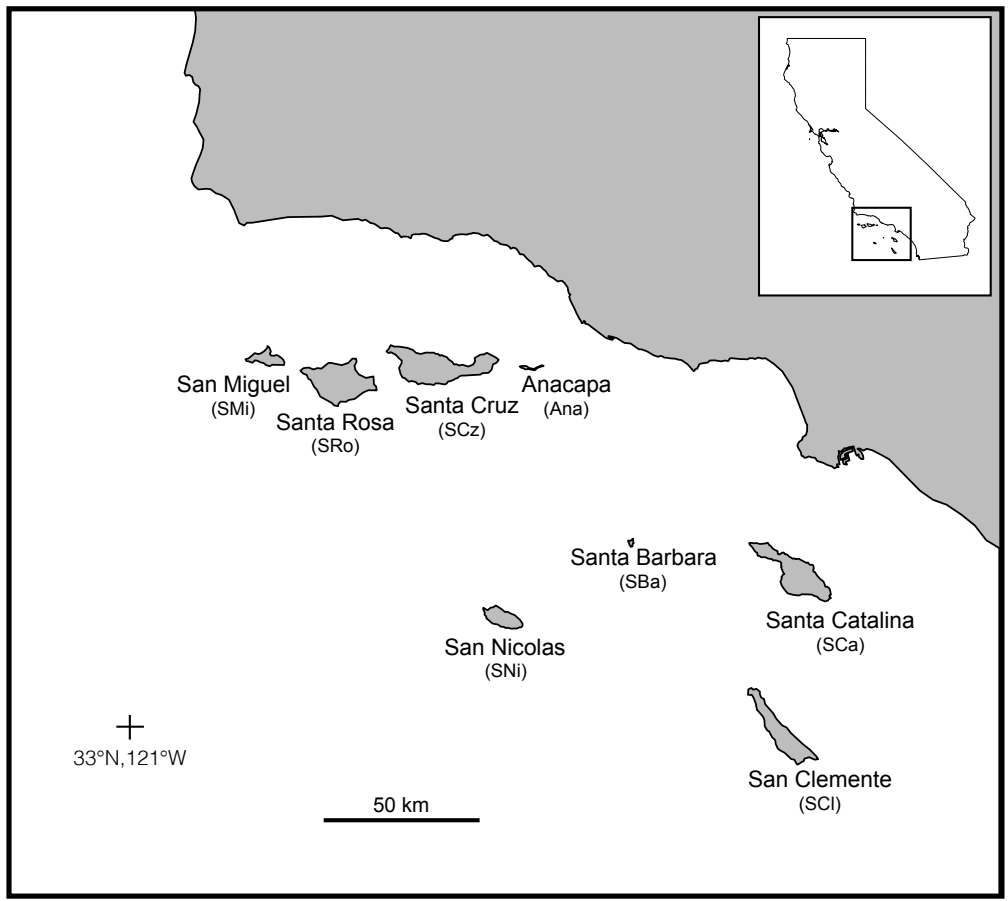

Fig. 1. Map of the California Channel Islands. The "northern islands" include San Miguel, Santa Rosa, Santa Cruz, and Anacapa. The "southern islands" include San Nicolas, Santa Barbara, Santa Catalina, and San Clemente.

islands via either sexually or asexually produced propagules. Perhaps even more importantly, if a population of a species already exists on an island, genetic continuity with the mainland may be maintained either by immigration of seeds, which might be dispersed via wind, water, or animals, or by animal- or winddispersed pollen. While the general biogeographic patterns of plants across islands have been documented across a range of biomes, lineages, and island sizes (see Cody 2006 for a particularly thorough example), plant biogeography has focused almost exclusively on seedproducing plants (but see Kreft et al. 2010, Patiño et al. 2014).

Spore-bearing plants (bryophytes, lycophytes, and ferns) are important components of island floras. These plants produce spores sexually (i.e., resulting from meiotic cell division), with spores typically $<100$ microns in diameter and thus easily wind dispersed. This predilection for wind dispersal has led to a higher proportion of pteridophytes on islands, relative to continents, across the globe (Kreft et al. 2010). Interestingly, this is despite the fact that spore-bearing plants tend not to diversify into island-endemic clades after colonization and instead typically persist as a single-island endemic species derived from the original colonizer (Patiño et al. 2014). In the case of relatively nearshore islands, gene flow among island and mainland populations of spore-bearing plants is often sufficient to prevent divergence, even in archipelagos with high seed plant endemism (Barrington 1993, Vanderpoorten et al. 2011). A useful way to approach the importance of these differences between spore-bearing and seed-bearing plants in assembling island floras is to directly compare spore-bearing and seed-bearing floras from the same archipelago (Aranda et al. 2013, Patiño et al. 2014).

In this study we address similarities and differences in the biogeography of bryophytes, ferns, and seed plants of the California Channel Islands (Fig. 1). The Channel Islands are particularly valuable because they have a wide range of size $\left(2.6-249 \mathrm{~km}^{2}\right)$, distance to mainland (20-98 km), maximum elevation $(253-753 \mathrm{~m})$, and latitude $\left(32.8^{\circ}-34.1^{\circ}\right)$. The islands have not been connected to the mainland since they last emerged above sea 
level (Junger and Johnson 1980, Vedder and Howell 1980, Atwater 1998, Schumann et al. 2012). However, the 4 northern islands have been variously connected to and isolated from one another with sea level fluctuations, with the most recent period of connection occurring at the Last Glacial Maximum. This continuous isolation of the islands from the mainland and, in the case of the southern islands, separation from one another, provide an opportunity to determine how dispersal limitation, or the lack thereof, influences species richness and composition across the islands.

The vascular flora (including both seed plants and pteridophytes) of the Channel Islands is well documented and has been the subject of extensive study over the last century (Ratay et al. 2014). Although the flora has benefitted from numerous floristic treatments (e.g., Wallace 1985, Junak et al. 1997), very little effort has been placed on understanding the mechanisms underlying biogeographic patterns of the flora. Moody (2000) provided the first quantitative investigation of patterns of total, native, and endemic richness with respect to island characteristics. He pointed out that while island area is an important and straightforward predictor of richness, the relationship of distance to mainland is more complicated, given the idiosyncrasies of island size and position across the archipelago. Riley and McGlaughlin (2015) further explored the relationship of mainland distance to species richness and found that incorporating distance to mainland along prevailing wind trajectories rather than straight-line distance to mainland greatly improved model fit. This study underscored the importance of wind dispersal in explaining current floristic patterns but did not address the fact that plants with strongly different dispersal mechanisms (e.g., spores vs. seeds) may be differentially influenced by wind dispersal. The difference between spore and seed dispersal has also been studied in the Macaronesian flora. In that archipelago, dispersal mode (spores/seeds) had no important effect on richness but impacted species composition across the studied islands (Aranda et al. 2013).

In this paper, we provide exploratory analyses aimed at asking 2 general questions. First, are patterns of species richness, and the importance of drivers of species richness (e.g., island area, distance to mainland), similar across spore-bearing and seed-bearing plants? Second, do patterns of species composition and beta diversity differ among sporebearing and seed-bearing plants? If so, what are the differences and how do they relate to island characteristics?

\section{Methods \\ Data Sets}

Data sets used for this study were taken from previously published species lists across the islands and include unpublished updates to the published floras. The vascular (seed plant and fern) species lists were updated from the list published by Ratay et al. (2014). The bryophyte flora was updated from the list published by Carter (2015). The vascular plant list is currently maintained by one of us (CMG) and includes several species that were not included in the 2014 list. The bryophyte list is currently maintained by the other author (BEC) and includes 2 species new for the islands and approximately 20 species new for San Nicolas Island since the 2015 publication. In both cases, analyses included only species presumed to be native to the Channel Islands. Lycophytes were included in the fern data set. For seed plant, fern, and bryophyte data sets, minimally ranked taxa were used, and we hereafter refer to these as taxa rather than species.

\section{Patterns of Species Richness}

To analyze patterns of richness across the islands, we regressed island richness against 5 predictor variables: island area, distance to mainland, maximum elevation, latitude, and prevailing wind distance. Prevailing wind distance, following Riley and McGlaughlin (2015), is the distance from each island to another propagule source (either mainland or island) along the direction of prevailing winds (see Riley and McGlaughlin [2015] for map, distances, and discussion). Using this metric, northern islands are most likely to receive wind-borne propagules from the mainland to the north, and Santa Catalina, a southern island, is most likely to receive propagules from the mainland to the east. The other southern islands, Santa Barbara, San Nicolas, and San Clemente, are more likely to receive propagules from the the northern islands rather than from the mainland. Area and distance to mainland are classical predictors of 
species richness (MacArthur and Wilson 1967), and we included maximum elevation because of the idiosyncratic topography of the Channel Islands, including the very small but relatively tall island of Anacapa and the fairly large but very low island of San Nicolas. Latitude was included because it reflects the strong precipitation gradient along the southern California coast. On the adjacent mainland, Santa Barbara (at similar latitude to the northern islands) has a mean annual precipitation of approximately $47 \mathrm{~cm}$, while San Diego, at a similar latitude to the southernmost island, has an annual precipitation of only $26 \mathrm{~cm}$ (NOAA 2017). Prevailing wind direction was included because, as discussed by Riley and McGlaughlin (2015), this variable may be a better predictor of richness for wind-dispersed plants than distance to mainland. Richness was regressed against raw predictors rather than log-transformed predictors because the raw predictors provide a better fit, as first observed for the Channel Islands by Moody (2000). For each of the 3 data sets (seed plants, ferns, bryophytes), we performed a multivariate regression including all variables as predictors. We then used Akaike's criterion (AIC) as implemented with the R function 'stepAIC' from the MASS package (Venables and Ripley 2002) to select an optimal multivariate model by removing uninformative predictors. We also performed separate univariate regressions for each of the 5 predictors for the bryophyte, fern, and seed plant data sets.

\section{Patterns of Species Composition}

To assess the correlation of each of the 3 taxon composition matrices (presences and absences of each taxon on each island) to each other, 3 Mantel tests were performed. These tests determine whether there were significant correlation structures between bryophytes and ferns, bryophytes and seed plants, and ferns and seed plants. The null hypothesis is no correlation among matrices. A rejection of the null would indicate that, for example, island pairs with highly dissimilar seed plant floras also have highly dissimilar bryophyte floras and island pairs with similar seed plant floras also have similar bryophyte floras. The Mantel tests were performed in $\mathrm{R}$ (https://www.r-project .org) using the 'mantel' function in the vegan package (Oksanen et al. 2017). Dissimilarity matrices were calculated for each of the 3 matrices using Jaccard dissimilarity. The Mantel tests were performed using the Pearson correlation method and employed 999 permutations. Mantel tests were also used to test for spatial autocorrelation in each of the 3 data sets by testing whether similarities among island floras correlate with similarities among island distances to one another.

Patterns of richness were also examined with separate principal component analyses of the 3 presence/absence matrices to identify clustering of the islands based on taxon composition. To determine which environmental factors drive the clustering patterns, we fit environmental vectors for the 5 environmental predictors to the ordinations using 'envfit' in the vegan package of $R$. This approach tests the fit of environmental variables to an ordination structure derived only from species distributions. It differs in this regard from canonical correspondence analysis (CCA) in that CCA explicitly employs data from the environmental matrix to inform the ordination structure and thus is subject to bias depending on selection of environmental variables. By fitting environmental variables to an existing ordination, the fitted environmental vectors approach is an unbiased test of fit of environmental variables to gradients derived only from species distributions.

To further explore the importance of latitude, we used a randomization procedure to test whether there is a statistically significant fraction of the flora that is unique to the northern islands and a separate fraction unique to the southern islands, as would be expected if there is floristic turnover between the northern and southern island groups. The procedure was conducted separately on all 3 matrices. In each case, the number of taxa restricted to the 4 northern islands and the number restricted to the 4 southern islands were calculated for the observed data sets. We then generated 999 randomized matrices in which taxa were randomly redistributed across the islands with the number of taxa per island held constant. To test whether there were more species restricted to the northern islands or to the southern islands than expected by chance, we calculated a $P$ value by comparing the proportion from the observed matrix with the distribution of proportions from the randomized matrices. All $P$ values calculated were one-tailed tests. 
Relative richness of plant groups across the Channel Islands

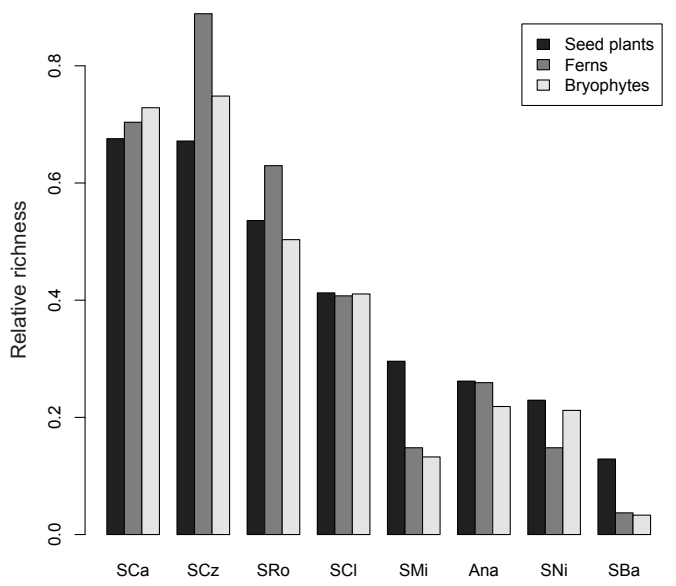

Fig. 2. Relative richness of seed plants, ferns, and bryophytes across the California Channel Islands. For each group, the island richness values were scaled by dividing by the total number of species in the group across the archipelago. Island abbreviations are given in Fig. 1.

\section{Partitioning of Beta Diversity}

Change in species composition among islands, or any sites, has 2 components: turnover and nestedness. Turnover is the replacement of a species at one site by a different species at another site (i.e., no gain or loss in number of species). Species can also be added or eliminated among sites (thereby increasing or decreasing pooled richness). Since sites with fewer species in this case are subsets of sites with more species, these sites are said to be nested. Because these 2 patterns, turnover and nestedness, can have different meanings with respect to the underlying colonization and extinction history, it is valuable to deconstruct beta diversity into the 2 components. Recently, Baselga (2010, 2012, Baselga and Orme 2012) devised a procedure for doing this by algebraically rearranging Sørenson dissimilarity, Jaccard dissimilarity, and Simpson dissimilarity to leverage the fact that Simpson dissimilarity takes into account only turnover, while the other 2 incorporate both turnover and nestedness. The dissimilarity metrics are calculated along with estimates of the distributions of the nestedness and turnover components of diversity. Analyses were performed in $\mathrm{R}$ using the betapart package (Baselga and Orme 2012). Only the seed plant and bryophyte matrices were analyzed because the fern matrix, with only 27 taxa, was to small to provide reliable distribution estimates. For the betapart analyses, 6 sites and 100 samples were used for computation of the distributions. These analyses are performed using only the presence/ absence matrices without regard to geographic factors like island area or distance to mainland, so the results must be interpreted with that in mind.

\section{RESULTS \\ Data Sets}

The number of taxa varied widely across the 3 data sets (seed plants: 737, ferns: 27, bryophytes: 151). The mean number of islands occupied was $3.21,3.22$ and 2.73 for the 3 taxonomic groups, respectively. And the percentage of taxa occurring on only a single island was fairly consistent across the data sets, with $29.9 \%, 25.8 \%$, and $29.8 \%$, respectively. The number of taxa occurring on all 8 islands was much higher for seed plants (30.4\%) than for ferns $(0 \%)$ and bryophytes (1.3\%).

\section{Patterns of Species Richness}

Proportional taxon richness across the islands was relatively uniform for seed plants, ferns, and bryophytes (Fig. 2). Fern richness was somewhat more idiosyncratic relative to seed plants and bryophytes, with relatively more taxa on Santa Cruz and Santa Rosa and fewer on San Nicolas. Seed plants had relatively high diversity on Santa Barbara and San Miguel Islands. Area and maximum elevation were both strong univariate predictors of richness for all 3 taxa, while distance to mainland was not a significant predictor for any (Fig. 3, Table 1). Additionally, distance along prevailing wind and latitude (a proxy for precipitation) were not strong univariate predictors of island richness (Table 1). In the multivariate regressions, AIC indicated that the optimal model for seed plants included all 5 predictors (Table 1). The optimal model for ferns excluded distance to mainland and latitude, and the optimal model for bryophytes excluded distance to mainland.

\section{Patterns of Species Composition}

The 3 Mantel tests demonstrated a strong similarity among each of the presence/absence matrices for the 3 plant groups. In each of the 3 pairwise comparisons, the tests rejected 

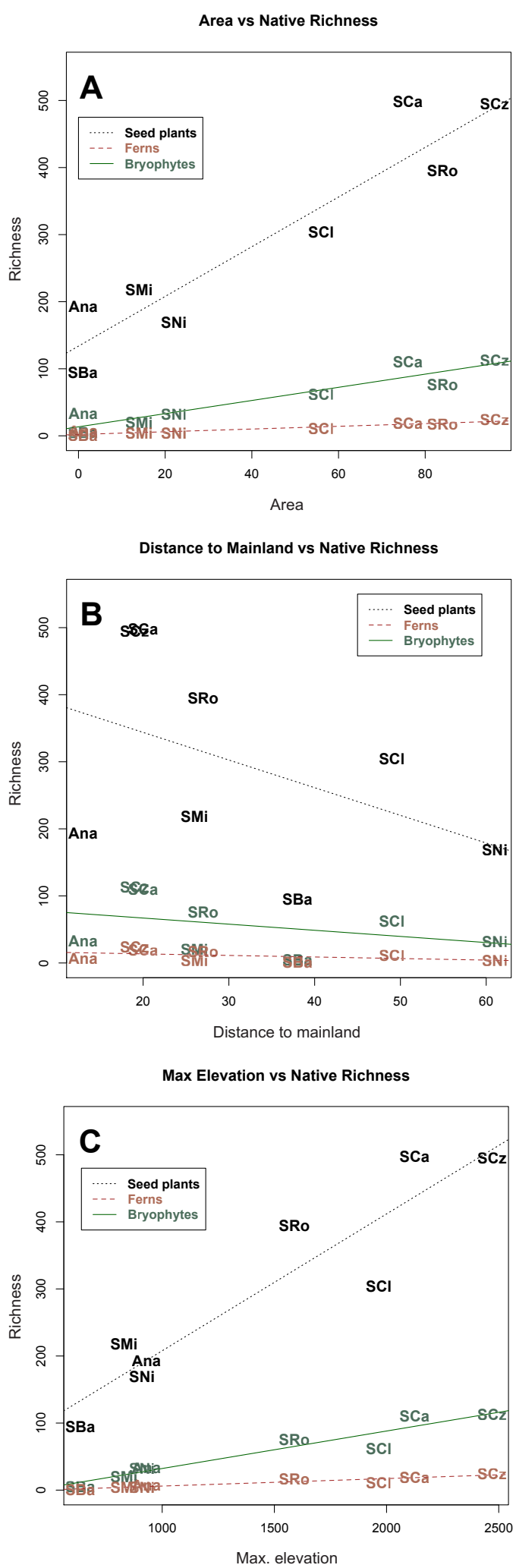

the null hypothesis of no correlation between matrices, indicating that patterns in floristic similarity among islands are relatively consistent among the 3 plant groups. Mantel r statistics and permutation values for each test were as follows: seed plants $\times$ ferns, $r=$ $0.849, P=0.001$; seed plants $\times$ bryophytes, $\mathrm{r}=0.751, P=0.001$; bryophytes $\times$ ferns, $\mathrm{r}=$ $0.830, P=0.001$.

Mantel tests comparing each of the 3 matrices against distances among islands (i.e., testing for spatial autocorrelation) all failed to reject the null, indicating no correlation between taxon composition and island distance. Mantel $r$ statistics and permutation values for each test were as follows: seed plants, $\mathrm{r}=$ $0.121, P=0.288$; ferns, $\mathrm{r}=0.139, P=0.704$; bryophytes, $\mathrm{r}=0.206, P=0.842$.

The ordinations of taxon composition were similar across the 3 plant groups (Fig. 4). In each case, the general pattern was a separation along the first principal component between the 4 larger and 4 smaller islands, and further separation within the large islands between north (Santa Cruz and Santa Rosa) and south (Santa Catalina and San Clemente). In seed plants and ferns, the smaller islands also formed northern (Anacapa and San Miguel) and southern (San Nicolas and Santa Barbara) subgroups, but the pattern did not hold for bryophytes. The other striking difference between the bryophyte ordination and the 2 vascular plant ordinations is the relative position of San Clemente in the bryophyte ordination. Its position near the origin indicates that there are few taxa unique to San Clemente, and also that there are few taxa that occur on both San Clemente and Santa Catalina but which are absent from the other 2 large islands, Santa Cruz and Santa Rosa.

The permutation tests fitting environmental predictors to the ordination structures were roughly similar across the 3 plant groups (Table 2 ). Area and maximum elevation were significantly correlated with the ordination structure for all 3 plant groups. Additionally, latitude had a low $P$ value (but nonsignificant after Bonferroni correction) suggesting a weak trend in the relationship for seed plants but no correlation with ferns or bryophytes. Distance to mainland

Fig. 3. Relationships of species richness with (A) area, (B) distance to mainland, and (C) maximum elevation. See Table 1 for $\mathrm{R}^{2}$ and $P$ values. 

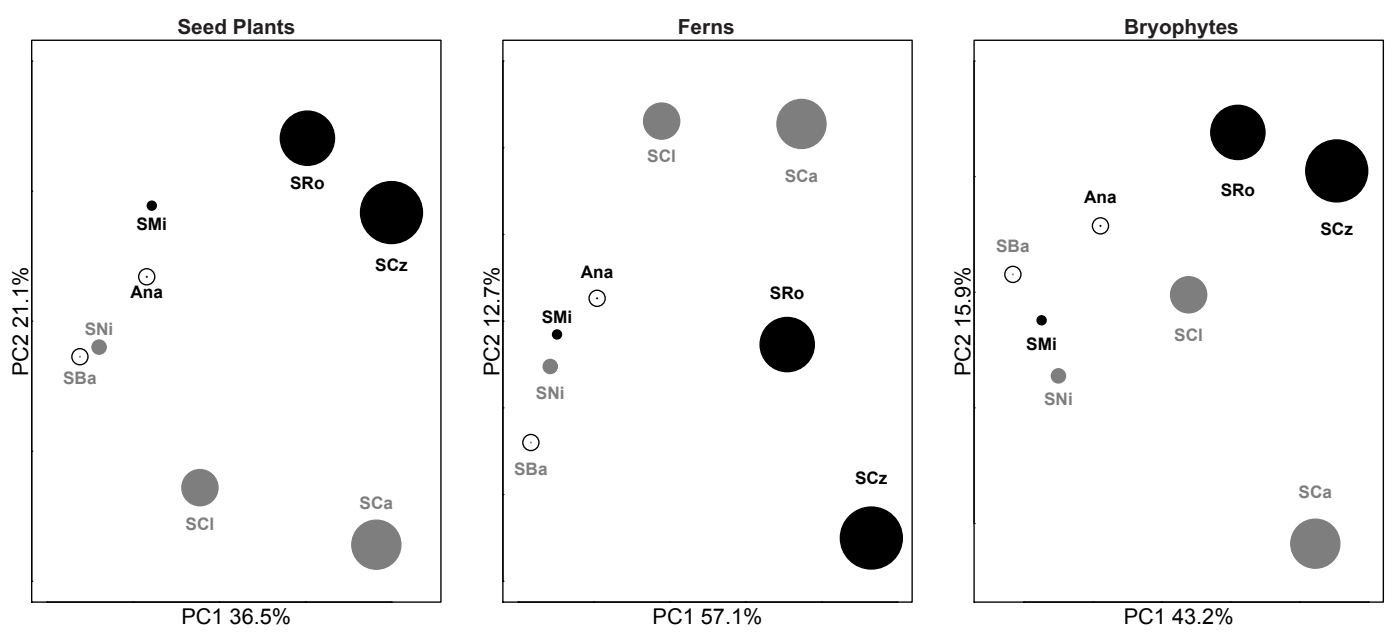

Fig. 4. Principal component analyses of the seed plant, fern, and bryophyte presence/absence matrices. Points representing islands are scaled by island size. Black points indicate northern islands and gray points indicate southern islands. Island abbreviations are given in Fig. 1.

TABLE 1. Summary statistics for univariate and multivariate regressions of island richness against 5 predictor variables. Adjusted $\mathrm{R}^{2}$ values and uncorrected $P$ values are presented for each univariate regression and for the optimal multivariate models selected by AIC. Boldface indicates that the predictor was included in the optimal multivariate model. Asterisks $(*)$ indicate significance at $\alpha<0.05$ using a Bonferroni-corrected $\alpha$ of 0.010 .

\begin{tabular}{|c|c|c|c|c|c|c|}
\hline & \multicolumn{2}{|c|}{ Seed plants } & \multicolumn{2}{|c|}{ Ferns } & \multicolumn{2}{|c|}{ Bryophytes } \\
\hline & Adj. $R^{2}$ & $P$ & Adj. $R^{2}$ & $P$ & Adj. $R^{2}$ & $P$ \\
\hline Distance to mainland & 0.064 & 0.2698 & 0.080 & 0.2517 & 0.007 & 0.3676 \\
\hline Area & 0.866 & $0.0005^{*}$ & 0.880 & $0.0040 *$ & 0.885 & $0.0006^{*}$ \\
\hline Max. elevation & 0.840 & $0.0008 *$ & 0.854 & $<0.0001 *$ & 0.897 & $0.0002 *$ \\
\hline Wind distance & 0.057 & 0.4607 & 0.049 & 0.4444 & 0.092 & 0.5449 \\
\hline Latitude & 0.144 & 0.7879 & 0.122 & 0.6432 & 0.002 & 0.9270 \\
\hline Multivariate model & 0.945 & 0.0391 & 0.985 & $<0.0001$ & 0.997 & 0.0001 \\
\hline
\end{tabular}

TABle 2. Permutation-based $P$ values for correlations between environmental variables and ordination structure of species composition for the 3 plant groups (see ordinations in Fig. 3). Asterisks (*) indicate significance at $\alpha<$ 0.05 using a Bonferroni-corrected $\alpha$ of 0.010 .

\begin{tabular}{lccc}
\hline & Seed plants & Ferns & Bryophytes \\
\hline $\begin{array}{l}\text { Distance to } \\
\text { mainland }\end{array}$ & 0.294 & 0.543 & 0.562 \\
Area & $0.009^{*}$ & $0.005^{*}$ & $0.005^{*}$ \\
Max. elevation & $0.005^{*}$ & 0.010 & $0.002^{*}$ \\
Wind distance & 0.291 & 0.516 & 0.865 \\
Latitude & 0.038 & 0.360 & 0.438 \\
\hline
\end{tabular}

and prevailing wind distance were not significantly correlated for any of the plant groups.

To further explore the influence of latitude, a randomization procedure was conducted to test whether higher proportions of species were restricted to the northern islands and southern
Table 3. Significance $(P)$ values from a randomization procedure with 999 permutations testing whether the northern islands and southern islands are more dissimilar than expected by chance. Low $P$ values indicate that the proportion of species restricted to the island group is higher than expected by chance. See text for details.

\begin{tabular}{lcc}
\hline & Northern islands & Southern islands \\
\hline Seed plants & 0.024 & $<0.001$ \\
Ferns & 0.094 & 0.080 \\
Bryophytes & 0.017 & 0.111 \\
\hline
\end{tabular}

islands than expected by chance (Table 3). For seed plants, the analysis indicated a significantly high proportion of species restricted to both the northern and southern islands; for bryophytes, only the northern islands had a significantly high proportion of unique species; for ferns, neither island group had a significantly high proportion of unique species. 


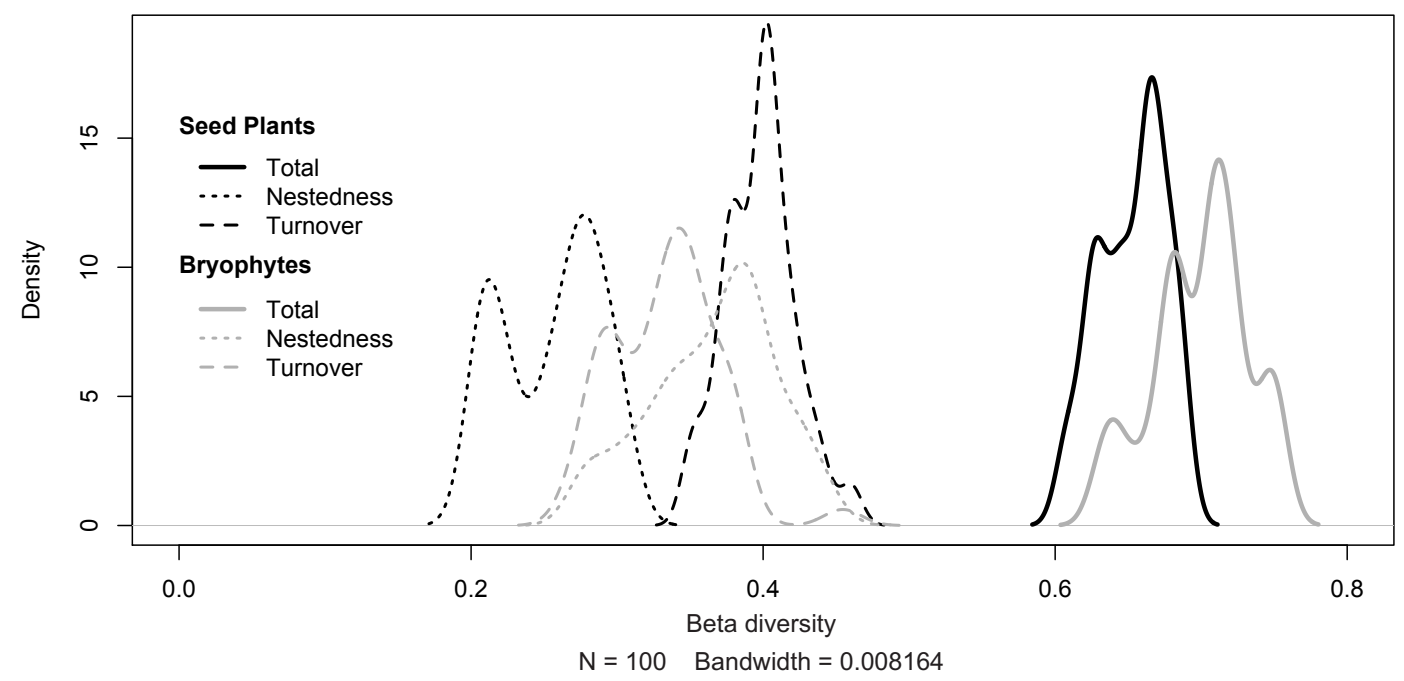

Fig. 5. Relative importance of turnover- and nestedness-resultant dissimilarity for seed plants and bryophytes.

\section{Partitioning Beta Diversity}

The betapart analysis aims to partition beta diversity, measured with the Sørenson dissimilarity index, into complementary components of turnover (i.e., Simpson dissimilarity) and nestedness (Sørenson dissimilarity minus Simpson dissimilarity). The results of the analyses of the seed plant and bryophyte matrices indicated slight but noteworthy differences between the 2 data sets (Fig. 5). For the bryophytes, the estimated partition of nestedness was slightly more important (higher along the $x$-axis) than the turnover component; however, the 2 distributions are largely overlapping, with very small displacement between the 2 peaks. For seed plants, the turnover partition is unambiguously of greater importance than the nestedness partition as indicated by the nonoverlapping estimated distributions for the 2 partitions.

\section{Discussion}

Despite large differences across the Channel Islands in overall taxon richness of the 3 plant groups considered here, patterns in taxon richness and composition are generally quite similar. This general observation is noteworthy because the proportions of endemics in the 3 floras (seed plants approximately 13\%, ferns $0 \%$, bryophytes approximately $1 \%$ ) suggest that gene flow, local adaptation, and other evolutionary drivers of diversification play different roles among these groups. Furthermore, island-specific land-use history (especially grazing), which is one of the potentially important determinants of species distributions across the islands, may impact these groups very differently.

\section{Species Richness}

Patterns of taxon richness of the native vascular flora (seed plants and ferns) have been addressed in at least 2 prior studies. Moody (2000) evaluated the importance of island area and distance to mainland for understanding richness of endemic, native, and introduced vascular plants. For native vascular species, that study documented a very strong correlation between island area and richness, with the residuals from that correlation strongly correlated with distance to mainland. The explanation for this correlation pattern is that area is by far the most important predictor of island richness, with some additional variation explained by distance to mainland. Moody (2000) proposed that differences in topography, land-use history, and number of vegetation types likely explained additional unexplained variation in the relationships, though these hypotheses were not tested. Riley and McGlaughlin (2015) conducted a separate analysis suggesting that prevailing wind patterns (primarily from the mainland through the northern islands toward the southern islands) are better predictors of 
endemic richness than distance to mainland. This approach, while focused on endemism rather than overall native richness, likely explains the generally poor fit between island richness and distance to mainland found in this study and by Moody (2000). The importance of wind dispersal is also apparent in Backs and Ashley's (2016) population genetic analysis of Quercus pacifica, which currently occurs on Santa Cruz, Santa Rosa, and Santa Catalina Islands. In an analysis of microsatellite data, Backs and Ashley (2016) found essentially no population structure corresponding to islands, with the implication that wind-dispersed pollen prevented isolation among the populations on separate islands.

Despite the obvious differences in dispersal propagules (unicellular spores in bryophytes and ferns; multicellular seeds in seed plants), we found similar patterns in the predictors of taxon richness across the islands for seed plants, ferns, and bryophytes. Island area and maximum elevation were very strong univariate predictors of richness for all 3 plant groups. Distance to mainland, prevailing wind distance, and latitude (a proxy for precipitation) were not strong univariate predictors of richness. These are the unambiguous similarities that dictate the broad patterns; however, there are also weak, but potentially biologically relevant, signals that suggest slight differences among the 3 groups. Neither distance to mainland nor prevailing wind distance were important univariate predictors of richness of any of the 3 groups. However, the AIC indicated a superior multivariate regression model fit (albeit with minimal improvement) with the inclusion of prevailing wind distance for all 3 groups and inclusion of distance to mainland for seed plants only. The pattern is not a strong one, but it is consistent with Riley and McGlaughlin's (2015) assertion that prevailing wind distance is important in understanding phytogeography on the Channel Islands. The inclusion of distance to mainland in the seed plant multivariate model but not in the bryophyte or fern models may be related to the fact that wind dispersal is the primary dispersal mode available to ferns and bryophytes, while the distributions of a proportion of seed plant lineages may be better explained by factors unrelated to prevailing winds, for example bird dispersal and ocean currents.

\section{Species Composition}

The long history of botanical exploration on the Channel Islands has yielded many observations on differences in species composition among the individual islands. Two general themes have been the influence of island size (and its correlate maximum elevation) and the differences between the northern and southern island groups. The larger, taller islands support species and vegetation types that do not occur on the lower and/or smaller islands. Classic examples include the island endemics Quercus tomentella and Lyonothamnus floribundus, each of which anchor vegetation types and associated understory species found only on the large islands. These examples presumably reflect habitat filtering, with the larger and taller islands having both more land area and maximum elevations that are high enough to access the marine fog layer. These 2 species are typically viewed as relicts that were more widespread across the archipelago historically but which are restricted today by current climatic conditions. The northern and southern island groups also each have distinctive floristic elements. Typical examples include the Pinus muricata forests of the northern islands and communities dominated by Cylindropuntia on the southern islands. These north/south differences have also typically been interpreted as relicts which reflect oscillations between $\mathrm{cool} /$ wet and warm/dry periods that have influenced vegetation patterns throughout southern California (Axelrod 1978, Axelrod and Govean 1996). Despite the presence of these potentially interesting patterns in species composition, quantitative analyses to date have focused on richness and endemism rather than on species composition (Moody 2000, Riley and McGlaughlin 2015) and have focused exclusively on vascular plants.

The analyses presented here demonstrate broad similarities in patterns of taxon composition across seed plants, ferns, and bryophytes, but also highlight several subtle differences that may be related to differences in life history among the 3 plant groups. One aspect of the archipelago that makes it particularly useful for investigating these similarities and differences is the lack of spatial autocorrelation among island floras. Using Mantel tests, we demonstrated that composition changes similarly in the 3 groups such that island pairs with dissimilar seed plant floras also 
have dissimilar fern and bryophyte floras, and island pairs with similar seed plant floras have similar fern and bryophyte floras as well. These similarities and differences, however, are not explained by geographic distance among islands (our Mantel tests for spatial autocorrelation found no pattern). This finding underscores the importance of the other factors we examined-namely distance to mainland, area, maximum elevation, prevailing wind distance, and latitude-in explaining patterns of taxon composition across the islands.

Similar to patterns in richness, island area and maximum elevation are correlated with differences in taxon composition for each of the 3 groups. This pattern is evident in the ordinations of the 3 taxon matrices (Fig. 3), which demonstrate a separation by island size (which is correlated with maximum elevation, $\mathrm{R}=0.82$ ) across the first principal component (the $x$-axes). Latitude also may play a weak role in species composition (see Fig. 3, principal component 2 , the $y$-axes) for seed plants but not for ferns or bryophytes; however, the statistical relationship is not significant after correction for multiple comparisons (Table 2). There is no indication in these results that dispersal limitation is a driving force dictating changes in taxon composition across the archipelago for any of the plant groups. If dispersal, either from the mainland or along prevailing wind distances, were strongly limited, we would expect that one or both of these predictors would be correlated with the ordination structure within the taxon matrices. The lack of correlation is consistent with the results for taxon richness, in which distance plays only a very minor role in explaining richness across the islands.

The only substantive difference in correlations of environmental factors with taxon composition of the 3 plant groups was in latitude. There was no relationship between latitude and the ferns and bryophytes; however, latitude did appear to play a weak (i.e., nonsignificant) but detectable role for seed plants (see separation between north and south islands along the $y$-axis in the seed plants ordination, Fig. 2). There is a strong latitudinal gradient of moisture availability across the Channel Islands, and the simplest explanation for the pattern in our results is that seed plant distributions are slightly more responsive to this strong moisture gradient. The results of the randomization tests (Table 3) are consistent with this interpretation. Those results confirm the intuition of generations of island botanists that there is a statistically supported suite of seed plants that occur only on northern islands and another suite of seed plants that occurs only on southern islands. There is thus substantial turnover between the northern islands and southern islands. This pattern is completely absent in the fern flora, although the very small number of fern taxa may play a role in the lack of statistical significance. In the bryophytes, there is a statistically supported suite of taxa that occur only on northern islands, but there is no such suite occurring only on southern islands. In general northern islands harbor most of the bryophyte taxa, while southern islands support a subset of the northern flora. This pattern of nesting contrasts starkly with the pattern of turnover exhibited in the seed plant flora.

\section{Nestedness and Turnover}

In biogeographic analyses, beta diversity has 2 components: nestedness and turnover. Nestedness occurs in a matrix when speciespoor islands support subsets of the species occurring on species-rich islands, with rare species being restricted to species-rich islands. The contrasting pattern, turnover, occurs when species are replaced from island to island, with species-poor islands containing species that do not occur on species-rich islands. One interpretation of matrices with strong turnover is that there is strong abiotic filtering. In contrast, possible explanations for strong nestedness include strong dispersal limitation or ordered extinction. If nestedness is due to dispersal limitation, islands farther from the mainland should have subsets of the species occurring on islands nearer to the mainland. The nested pattern thus results from constraints limiting dispersal of some species to the farthest islands. If nestedness is caused by ordered extinction, islands subject to the agent causing extinction will have subsets of those species protected from the agent causing extinction.

Consistent with the other analyses of species composition, our beta-partitioning analysis indicated that signals of nestedness and turnover were comparable within the bryophyte matrix, but that turnover was more 
important than nestedness in the seed plant matrix. Although this analysis is an exploratory approach that does not have an associated measure of significance, the general pattern of a stronger signal of turnover in the seed plant matrix is consistent with results from the ordinations and randomization test.

Our interpretation, based on these results, is that habitat filtering (likely based on moisture availability in this case) plays a larger role in seed plant composition, as expressed in higher turnover between the wetter northern islands and drier southern islands. The bryophyte flora, which lacks a suite of taxa adapted to the dry conditions on the southern islands, exhibits a nested pattern, with most of the rare taxa tending to occur on the wetter northern islands. This result is consistent with a study by Patiño et al. (2014) which examined fern, bryophyte, and seed plant diversification across oceanic island archipelagos. That study focused on the fact that islands tend to produce radiations of endemic seed plants, whereas fern and bryophyte island endemics tend not to diversify on islands. Greater dispersal among spore-bearing plants is one mechanism for this difference in diversification. However, another important mechanism is the tendency for bryophytes and ferns to maintain physiologically broad tolerances, whereas seed plants tend to undergo local adaptation (see discussion in Patiño et al. 2014). This mechanism could help to explain higher rates of endemism in seed plants (in conjunction with dispersal limitation) but also suggests that species turnover caused by fine-niche partitioning may be much more prevalent in seed plants than in bryophytes.

In the case of the Channel Islands, differences in relictualism may also play a role. The seed plant flora exhibits relictual vegetation types (e.g., the bishop pine forests) exclusively on the northern islands that are common on mainland sites to the north but absent on the adjacent mainland. Similarly, the southern islands have relictual vegetation (e.g., cactusdominated bluff scrub) that is mostly absent on the adjacent mainland but present on the mainland to the south. Species following these patterns reinforce the pattern of floristic turnover between the northern and southern island groups. The bryophyte flora exhibits similar relictualism on the wetter northern islands, but there are very few species associated with the dry scrub vegetation types unique to the southern islands.

In summary, the broad trend in our analyses was that the seed plant, fern, and bryophyte floras exhibit mostly similar patterns in richness and composition across the Channel Islands. By far, island size and maximum elevation are the most important factors explaining differences in both richness and composition for all 3 groups of plants. We found only weak support for a role of dispersal limitation in explaining patterns of richness and no important role of dispersal limitation in explaining differences in composition for any of the 3 plant groups. There were 2 differences among plant groups. We found a slightly greater importance for dispersal limitation in seed plants relative to ferns and bryophytes in explaining species richness. Second, there was strong turnover of the seed plants between the northern and southern islands, whereas nestedness was more the important pattern for bryophytes.

\section{ACKNOWLEDGMENTS}

This work would not have been possible without the efforts of many botanists, both in the field and in the herbarium, who have worked to document the flora of the Channel Islands. The authors are grateful to M.E. McGlaughlin for insightful discussions on the phytogeography of the archipelago and to 2 anonymous reviewers who suggested substantial improvements to an earlier draft.

\section{Literature Cited}

Aranda, S.C., R. Gabriel, P.A.V. Borges, A.M.C. Santos, J. Hortal, A. Baselga, And J.M. Lobo. 2013. How do different dispersal modes shape the species-area relationship? Evidence for between-group coherence in the Macaronesian flora. Global Ecology and Biogeography 22:483-493.

ATwATER, T.M. 1998. Plate tectonic history of southern California with emphasis on the western Transverse Ranges and northern Channel Islands. In: P.W. Weigand, editor, Contributions to the geology of the Northern Channel Islands, Southern California. American Association of Petroleum Geologists, Pacific Section, Miscellaneous Publication 45:1-8.

AXELROD, D.I. 1978. The origin of coastal sage vegetation, Alta and Baja California. American Journal of Botany 65:1117-1131.

Axelrod, D.I., And F. Govean. 1996. An early Pleistocene closed-cone pine forest at Costa Mesa, southern California. International Journal of Plant Science 157:323-329. 
BaCKS, J.R., AND M.V. Ashley. 2016. Evolutionary history and gene flow of an island oak: Quercus pacifica. American Journal of Botany 103:2115-2125.

BARRINGTON, D.S. 1993. Ecological and historical factors in fern biogeography. Journal of Biogeography $20: 275-279$

BASELGa, A. 2010. Partitioning the turnover and nestedness components of beta diversity. Global Ecology and Biogeography 19:134-143.

BAselga, A. 2012. The relationship between species replacement, dissimilarity derived from nestedness, and nestedness. Global Ecology and Biogeography 21:1223-1232.

Baselga, A., and C.D.L. Orme. 2012. Betapart: an R package for the study of beta diversity. Methods in Ecology and Evolution 3:808-812.

Carter, B.E. 2015. A checklist of the bryophytes of the California Channel Islands. Madroño 62:186-207.

Cody, M. 2006. Plants on islands. University of California Press, Berkeley, CA.

Junak, S., R. Philbrick, S. Chaney, and R. Clark. 1997. A checklist of vascular plants of Channel Islands National Park. 2nd edition. Southwest Parks and Monuments Association, Tucson, AZ.

Junger, A., AND D.L. JoHnson. 1980. Was there a Quaternary land bridge to the northern Channel Islands. Pages 33-39 in D.M. Power, editor, The California islands: proceedings of a multidisciplinary symposium. Santa Barbara Museum of Natural History, Santa Barbara, CA. Haagen Printing, Santa Barbara, CA.

Kreft, H., W. Jetz, J. Mutke, and W. Barthlott. 2010. Contrasting environmental and regional effects on global pteridophyte and seed plant diversity. Ecography 33:408-419.

MacArthuR, R.H., AND E.O. Wilson. 1967. The theory of island biogeography. Princeton University Press, Princeton, NJ.

Moody, A. 2000. Analysis of plant species diversity with respect to island characteristics on the Channel Islands, California. Journal of Biogeography 27: $711-723$.

[NOAA] National OCEANiC AND ATMOSPheric AdminisTRATION. 2017. Data retrieved from the NOAA Earth System Research Laboratory website; [accessed 8 January 2017]. https://www.esrl.noaa.gov/psd

Oksanen, J., F.G. Blanchet, M. Friendly, R. Kindt, P. Legendre, D. McGlinn, P.R. Minchin, R.B. O'Hara,
G.L. Simpson, P. Solymos, ET AL. 2017. vegan: Community Ecology Package. R package version 2.4-3.

Patiño, J., M. Carine, J.M. Fernández-Palacios, R. Otto, H. Schaefer, and A. Vanderpoorten. 2014. The anagenetic world of spore-producing land plants. New Phytologist 201:305-311.

Ratay, S.E., S.E. VanderPlanK, and B.T. Wilder. 2014. Island specialists: shared flora of the Alta and Baja California Pacific Islands. Monographs of the Western North American Naturalist 7:161-220.

Riley, L., and M.E. McGlaughlin. 2015. Endemism in native floras of California's Channel Islands correlated with seasonal patters of Aeolian processes. Botany 94:65-72.

Schumann, R.R., S.A. Minor, D.R. Muhs, L.T. Groves, AND J.P. McGeEhin. 2012. Tectonic influences on the preservation of marine terraces: old and new evidence from Santa Catalina Island, California. Geomorphology 179:208-224.

Vanderpoorten, A., B. Laenen, F. Rumsey, J.M. GonZÁlez-Mancebo, R. Gabriel, and M. Carine. 2011. Dispersal, diversity and evolution of the Macaronesian cryptogamic floras. Pages 338-364 in D. Bramwell and J. Caujapé, editors, Plants and islands. 2nd edition. Cambridge University Press, Cambridge, United Kingdom.

Vedder, J.G., AND D.G. Howell. 1980. Topographic evolution of the southern California borderland during late Cenozoic time. Pages 7-32 in D.M. Power, editor, The California islands: proceedings of a multidisciplinary symposium. Santa Barbara Museum of Natural History, Santa Barbara, CA. Haagen Printing, Santa Barbara, CA.

Venables, W.N., AND B.D. Ripley. 2002. Modern applied statistics with S. 4th edition. Springer, New York, NY.

WaLLaCE, G.D. 1985. Vascular plants of the Channel Islands of southern California and Guadalupe Island, Baja California, Mexico. Contributions in Science 365, Natural History Museum of Los Angeles County, Los Angeles, CA.

Received 27 February 2017

Revised 24 January 2018 Accepted 6 April 2018

Published online 12 December 2018 